\title{
MODELO BIM INTEGRADO GERINDO O FLUXO DE INFORMAÇÕES NO PROCESSO DE PROJETO
}

\section{INTEGRATED BIM MODEL MANAGING THE FLOW OF INFORMATION IN THE DESIGN PROCESS}

\author{
Roberta Augusta Menezes Lopes de Barros ${ }^{1}$ \\ Universidade Federal de Santa Catarina, Florianópolis, SC, Brasil, roberta.mlb@gmail.com \\ Lisiane Ilha Librelotto ${ }^{2}$ \\ Universidade Federal de Santa Catarina, Florianópolis, SC, Brasil, lisiane.librelotto@gmail.com \\ Franchesca Medina ${ }^{3}$ \\ Universidade Federal de Santa Catarina, Florianópolis, SC, Brasil, fr.medn@gmail.com
}

\begin{abstract}
Resumo
A etapa de elaboração de projeto é uma das fases mais importantes para a qualidade do empreendimento, pois são definidos todos os parâmetros de uma proposta. Além do mais, a criação, a compatibilização e visualização do projeto passaram por mudanças a partir da adoção do BIM. Assim, é necessário que ocorra um controle das informações e uma gestão eficiente do processo. Este artigo tem como objetivo mapear o processo de projeto e o fluxo de informações em BIM em empresas de arquitetura na cidade de Florianópolis/SC. Esta pesquisa faz uso de diferentes instrumentos de coleta de dados: formulário de caracterização; questionário; análise da documentação e entrevistas. Os resultados apresentados neste artigo correspondem a um caso analisado, de um total de três casos estudados na pesquisa de mestrado. Observou-se que a disciplina de Projeto de Arquitetura foi que norteou o processo, tendo sido utilizado um modelo integrado pela disciplina de Arquitetura. Os resultados indicaram que o processo de projeto no caso analisado foi integrado, mas não simultâneo, as entregas de projeto das demais disciplinas ocorreram em datas distintas. Foram identificadas vantagens e desvantagens, destacando-se como benefício maior controle da informação, melhor interação entre os profissionais envolvidos no processo, facilidade de visualização do projeto, melhoria da compatibilidade entre as disciplinas. Já as desvantagens foram associadas a uma aderência parcial dos envolvidos à disponibilização dos modelos de informação nos prazos estipulados e a variedade de ferramentas BIM e CAD utilizadas assim como projetos entregues em PDF dificultando a interoperabilidade e reuso de modelagens.
\end{abstract}

Palavras-chave: Modelagem da Informação da Construção. Gestão do processo de projeto. Fluxo de informações. Modelo integrado.

\begin{abstract}
The design development stage is one of the most important stages for the quality of the project, as all parameters of a proposal are defined. Furthermore, the creation, coordination and visualization of the project has undergone changes since the adoption of BIM. Thus, it is necessary to have information control and efficient process management. This article aims to map the design process and the flow of information in BIM in architecture companies in the city of Florianopolis, SC. This research uses different data collection instruments: characterization form, questionnaires, analysis of documentation, and interviews. The results presented in this article correspond to one case analyzed, out of a total of three cases studied in the corresponding master's research. It was observed that the discipline of Architecture guided the process, using an integrated model. The results indicated that the design process in the analyzed case was integrated, but not simultaneous; the project deliveries of the other disciplines took place on different dates. Advantages and disadvantages were identified, highlighting the benefit of greater information control, better interaction between professionals involved in the process, ease of visualization of the project, improved compatibility between disciplines. The disadvantages were associated with a partial adherence of those involved in the availability of information models within the stipulated deadlines, the variety of BIM and CAD tools used, and projects delivered in PDF, making interoperability and modeling reuse difficult.
\end{abstract}

Keywords: Building Information Modeling. Process management. Information flow. Integrated model.

How to cite this article:

BARROS, R. A. M. L. DE; LIBRELOTTO, L. I.; MEDINA, F. Modelo BIM integrado gerindo o fluxo de informações no processo de projeto. PARC Pesquisa em Arquitetura e Construção, v. 11, p. e020010, 13 jul. 2020.

DOI:https://doi.org/10.20396/parc.v11i0.8653830 


\section{Introdução}

A partir da adoção do processo de projeto baseado na Modelagem da Informação da Construção ou BIM (Building Informatiom Modeling), o modo de projetar, compatibilizar e visualizar o projeto passou por mudanças, com o surgimento de novos conceitos e metodologias. Ocorre a transição do pensamento em projeto baseado na representação bidimensional para a modelagem virtual tridimensional (COSTA, 2015; OLIVEIRA, et al., 2017). Esse novo cenário é favorável para o avanço de práticas de projeto colaborativo e integrado como afirmam Azhar, Khalfam e Maqsood (2015) ao descreverem que o BIM corresponde a um novo paradigma de projeto.

A etapa de elaboração de projeto corresponde a uma das fases mais cruciais para a qualidade do empreendimento, pois são definidos todos os parâmetros da proposta. $O$ BIM tem como característica principal o intercâmbio de informações com intuito de melhorar a tomada de decisão pelos projetistas em fases preliminares de projeto (BARISON; SANTOS, 2016; FARINA; COELHO, 2015). Deste modo, é necessário um controle do compartilhamento de informações e uma gestão eficiente para otimização do processo de projeto.

Os conflitos que ocorrem na etapa de elaboração de projetos, podem estar associados a inconsistência das informações e a insuficiência dos dados (COSTA, 2015). Com o uso das ferramentas BIM isso pode ser minimizado, pois quando os envolvidos no projeto interagem desde o início, conseguem vislumbrar antecipadamente conflitos entre soluções ou não atendimento à requisitos do projeto (EASTMAN et al., 2014).

A deficiência no intercâmbio das informações pode resultar em diversos problemas de ordem técnica, financeira, estética e até interferir na qualidade do projeto, e uma das principais razões para esta deficiência é uma comunicação ineficaz (ROMANO; BACK; OLIVEIRA, 2001). Assim, o processo BIM é considerado como um importante aliado na elaboração de projetos, pois instiga a colaboração e a integração entre as diferentes disciplinas de projeto auxiliando a tomada de decisão.

Deste modo, o trabalho tem como objetivo principal realizar uma análise comparativa de fluxos de informação entre processo de projeto tradicional e com BIM. O estudo foi realizado em escritório de projeto de arquitetura na cidade de Florianópolis/SC. Buscouse caracterizar o fluxo de dados e de informações entre as disciplinas envolvidas no processo de projeto em BIM. A ênfase da pesquisa está na análise das etapas e atividades desenvolvidas durante o processo de projeto envolvendo as disciplinas de projeto com foco em arquitetura.

Assim, a pesquisa está delimitada ao processo de projeto de arquitetura em BIM, e não leva em consideração a adoção e o uso do BIM na construção, e no uso e operação do edifício. $O$ estudo não considera o processo de trabalho das demais disciplinas, apenas as entregas realizadas pelos projetos complementares no desenvolvimento do Projeto de Arquitetura, e também não aborda a utilização e comunicação dos softwares BIM durante o processo de projeto, sendo este, apenas um critério de seleção e escolha do caso analisado.

\section{Fundamentação}

A Modelagem da Informação da Construção instiga a troca e compartilhamento das informações por parâmetros (fixos ou variáveis) inseridos no modelo, a fim de aperfeiçoar a tomada de decisão pelos projetistas em fases iniciais de projeto, isto de modo integrado (EASTMAN et al., 2014; ARCARI et al., 2015). O intuito é diminuir os retrabalhos e possibilitar uma melhor eficiência no processo de projeto. 
Há um consenso de que ocorrem alterações relacionadas a questões conceituais e culturais significativas referentes ao dia-a-dia e a rotina de trabalho a partir do uso do BIM que vão além da aquisição e uso dos softwares (MENEZES, 2011). Conforme menciona Arayici et al. (2011), as mudanças não correspondem apenas no aprendizado dos softwares, mas na reformulação do fluxo de trabalho, no treinamento e atribuições profissionais, e na modelagem do edifício. O BIM não está associado apenas à aplicação de ferramentas computacionais, mas também aos aspectos de integração, colaboração, interoperabilidade e multidisciplinaridade (SOUZA; AMORIM; LYRIO, 2009). Como sintetiza Maia (2016, p.41) “o BIM vai além de uma ferramenta de elaboração de projetos ou de gestão de obra. Trata-se da integração de informações provenientes de pessoas, processos e tecnologia".

Eastman et al. (2014, p.21) ressaltam que "colaborações mais cedo entre o arquiteto, o empreiteiro e outras disciplinas de projeto serão necessárias, já que o conhecimento fornecido pelos especialistas é de uso mais intenso durante a fase de projeto". Todavia, para que ocorra a real incorporação do BIM na gestão de projetos, alguns entraves precisam ser sanados, pois o BIM servirá de subsídio a prática de gestão e sem uma mudança da rotina de trabalho, as ferramentas serão utilizadas apenas como recurso tecnológico (FERREIRA; SANTOS, 2015).

Segundo Kowaltowski et al. (2011, p.75) “A adoção integral das práticas recomendadas de gestão do processo de projeto, em muitos casos, reduz os índices de retrabalho, da fase de projeto até a entrega das obras". Conforme ressalta Melhado et al. (2005 apud BOMFIM; MATOS; LISBOA, 2016, p.2) "a coordenação de projetos é uma atividade de suporte ao desenvolvimento do processo do projeto voltada à integração dos requisitos e das decisões de projeto". Com base nestas afirmativas, pode-se afirmar que o BIM é visto como um importante aliado para o gerenciamento de projetos, referente ao empreendimento. Para Rokooei (2015, p. 5), o BIM é uma ferramenta eficaz e poderosa na gestão de projetos na indústria da construção.

A gestão da informação na construção, praticada de forma eficiente, possibilita um ganho na qualidade do projeto a partir da redução de prazos e custos (MONTEIRO; MARTINS, 2011). A utilização da Modelagem da Informação da Construção no processo de elaboração de projetos instiga uma melhor definição do fluxo de trabalho e com isso o compartilhamento dos dados (PEREIRA; AMORIM, 2016).

Deste modo, compreende-se que a informação é essencial para a criação e avaliação de projetos em BIM, no entendimento de quanto mais conhecimento da informação disponível, maior é a probabilidade de ter um produto de qualidade. Como afirmam Campestrini et al. (2015, p.9) "Sob o ponto de vista do BIM, a colaboração precisa de gestão da informação, pois é por meio da informação que há interação entre os profissionais".

Ainda segundo Campestrini et al. (2015) a gestão da informação no desenvolvimento de projetos gera impacto na qualidade final do produto, e é de suma importância que as informações estejam disponíveis aos profissionais em todas as etapas do projeto. Em razão de que as tomadas de decisão realizadas sem precisão geram retrabalho ou afetam na qualidade do projeto (CAMPESTRINI et al., 2015).

No decorrer do projeto, o processo vai se tornando cada vez mais complexo devido ao volume de informações e seus relacionamentos, com isso, é imprescindível que ocorra um controle e monitoramento do fluxo de informações. Como descrevem Chen et al. (2015, p. 1) "O principal objetivo da gestão da informação é apoiar a tomada de decisões, garantindo que as informações estão sempre disponíveis no momento certo no formato certo para a pessoa certa". 
Referente à lacuna do conhecimento foi realizado um levantamento, de 2007 a 2017, em publicações científicas (artigos) e produções acadêmicas (monografias, dissertações e teses) relacionadas à temática. A coleta ocorreu a partir de termos que envolvem o BIM e gestão do processo, com variações e expressões correlatas ("Building Information Modeling" OR "BIM" AND "project process management" OR "project management" OR "design process" AND "information modeling management" OR "information management" OR "information modeling" AND "interoperability" OR "exchange of information"). Pela revisão de literatura foi verificado que as principais abordagens associadas ao BIM consistem em: (1) adoção do BIM no âmbito profissional; (2) inserção do BIM no âmbito acadêmico; (3) aplicações do BIM em projeto com diferentes abordagens (interoperabilidade, coordenação, simulação, entre outras).

Observou-se que a temática da adoção do BIM no âmbito profissional enfatiza a implantação do BIM com foco nos benefícios, impactos e desafios gerados (SOUZA; AMORIM; LYRIO, 2009; SOUZA et al., 2012; MIGILINSKASA et al., 2013; DELATORRE; SANTOS, 2014; COELHO; SILVA; MELHADO, 2015). Entretanto, alguns estudos se aprofundaram na compreensão da gestão de projetos e fluxo de informações após o BIM. Exemplos de pesquisas que caracterizam este assunto são Elmualim e Gilder (2013), Antunes e Scheer (2014), Durante et al. (2015), Barros e Silva (2016) e Maia (2016).

Elmualim e Gilder (2013) verificaram a mudança da adoção do BIM referente a gestão de projeto, com foco na colaboração. Antunes e Scheer (2014) analisaram os processos e fluxos de informações de projeto de estruturas de concreto armado utilizando sistemas BIM, com ênfase na metodologia IDM (Information Delivery Manual). Já Durante et al. (2015) observaram que após o BIM o processo obteve benefícios quanto a velocidade e dinamismo de detecção e resolução de problemas, melhorando assim a qualidade das soluções apresentadas.

Barros e Silva (2016) realizaram uma revisão sistemática de literatura (RSL) com ênfase em publicações sobre a avaliação do ciclo de vida de edificações (ACV) aliada ao Building Information Modeling (BIM) com a análise dos fluxos de trabalho de avaliação tradicional em comparação ao fluxo de trabalho mediado por BIM. Já o estudo desenvolvido por Maia (2016) teve como foco a análise do fluxo de informações no processo de manutenção predial apoiada no BIM.

No que se refere à inserção do BIM no âmbito acadêmico, os estudos abordaram a aplicação do BIM em Universidades e cursos técnicos destacando os obstáculos a serem superados para reestruturação curricular: Ruschel, Andrade e Morais (2013), Checcucci (2014) e Cruz, Cuperschmid e Ruschel (2017). Bem como, deram ênfase as competências e habilidades que devem ser ensinadas para que os estudantes se tornem profissionais aptos ao novo cenário como apresentado nos estudos desenvolvidos por Barison e Santos (2012) e Delatorre (2014) em sua pesquisa de mestrado.

Em relação às aplicações do BIM em projeto com diferentes abordagens observou-se que os estudos descreveram as potencialidades e desafios da adoção do BIM, a partir de comparativos entre o processo tradicional e o processo BIM, como realizado por Goes e Santos (2011) e Barros e Silva (2016). Sendo também abordado o conceito da interoperabilidade com o uso do formato IFC focando no fluxo de informações entre as disciplinas de projeto desenvolvidos por Müller (2011) e Carvalho (2012).

Baseado nos resultados obtidos, com o levantamento dos estudos apresentados, foi identificado que questões relacionadas ao mapeamento do fluxo de trabalho e a troca e compartilhamento das informações baseadas no Projeto de Arquitetura em BIM devem ser mais exploradas. Sendo necessário focar na gestão do processo, visto que lidar com a informação é o ponto chave da Modelagem da Informação da Construção. 


\section{Método}

A abordagem da pesquisa é qualitativa e tem como estratégia de investigação o estudo de caso. Segundo Creswell (2007) a pesquisa qualitativa possui caráter exploratório, uma vez que o pesquisador não possui conhecimento das variáveis nas quais está se propondo a pesquisar, sendo assim um processo bastante indutivo. Já Yin (2001, p.32) expõe que um estudo de caso se caracteriza como "uma investigação empírica que investiga um fenômeno contemporâneo dentro de seu contexto da vida real."

Florianópolis/SC foi selecionada pelo seu caráter tecnológico e pela exigência da entrega de projeto em BIM pelos órgãos do Governo do Estado nas licitações, influenciando mudanças significativas no modo de projetar das empresas de arquitetura atuantes no mercado de trabalho desta cidade. De acordo com informações disponíveis no portal MAKEBIM (2016), o Governo de Santa Catarina é pioneiro no Brasil em lançar editais para contratação de projetos em BIM.

Os critérios de escolha dos casos corresponderam à adoção e uso do BIM no processo de elaboração de projeto, bem como a disponibilidade e interesse da empresa em participar da pesquisa. Os parâmetros levados em consideração foram: que as empresas utilizassem as ferramentas BIM no processo de projeto; que possuíssem sede na cidade de Florianópolis/SC; e que atuassem no segmento de projetos arquitetônicos. Vale ressaltar que esta pesquisa foi submetida ao Comitê de Ética através da Plataforma Brasil $^{(1)}$ seguindo as recomendações estabelecidas pelo sistema.

A pesquisa de mestrado abordou três projetos de arquitetura com diferentes escalas e níveis de complexidade na cidade de Florianópolis/SC, em três locais distintos. Em uma Instituição do Governo do Estado e duas empresas de arquitetura. Entretanto, neste artigo são apresentados os resultados obtidos em um único projeto, desenvolvido por um escritório de arquitetura. Para a caracterização dos casos foi levado em consideração três pontos principais: Caracterização da Empresa; Caracterização do Projeto; Caracterização dos Participantes.

A aplicação da pesquisa foi estruturada a partir da elaboração e verificação de um roteiro de coleta de dados fundamentado no objetivo da pesquisa. Os dados foram adquiridos por meio do preenchimento do formulário de caracterização (da empresa, projeto, e dos participantes da pesquisa), da aplicação do questionário, da análise da documentação e aplicação de entrevista semiestruturada e aberta.

Inicialmente foi realizado um contato por e-mail com as empresas selecionadas, explicando os pontos principais da pesquisa e descrevendo como o estudo seria conduzido. Enfatizou-se neste momento os aspectos de anonimato e confidencialidade. Após isto, foi agendada uma reunião para conhecer o ambiente e os profissionais, e assim escolher o projeto de arquitetura que seria analisado. Após concordância iniciouse a coleta dos dados fundamentada no Termo de Consentimento Livre e Esclarecido (TCLE). Vale enfatizar que cada exploração estava condicionada a quantidade de informações do projeto, bem como a disponibilidade de dados para análise.

Com o intuito de complementação e aquisição de uma maior coerência e consistência das informações obtidas no estudo foram utilizados diferentes instrumentos de coleta de dados, e estes foram elaborados seguindo os parâmetros delimitados abaixo:

- FORMULÁRIO (04 questões): compreensão das atividades desempenhadas, a partir da caracterização da empresa, do projeto, e dos participantes da pesquisa.

- QUESTIONÁRIO (20 questões): caracterizado por uma análise dos aspectos quanto à atuação da empresa no mercado de trabalho, a delimitação das vantagens, 
dificuldades, melhorias e principais mudanças com a adoção do BIM. Bem como a identificação dos meios de comunicação utilizados para a troca e compartilhamento das informações e as ferramentas computacionais empregadas durante o processo.

- ENTREVISTAS: foram estruturadas em dois blocos, o primeiro com 05 perguntas semiestruturadas e o segundo com 15 perguntas abertas. As questões correspondem ao processo de projeto em BIM, a interação com as demais disciplinas envolvidas, a troca e o compartilhamento das informações, ao gerenciamento destas informações e a gestão do processo de projeto em BIM.

- DOCUMENTAÇÃO (08 tópicos): consiste em uma análise da estrutura organizacional da empresa, do fluxo de trabalho e informações durante o processo de projeto. Como também uma investigação dos procedimentos de planejamento e controle do processo de projeto, e de monitoramento e controle do fluxo de informações.

A aquisição dos dados com o formulário e o questionário consiste no entendimento da estrutura organizacional da empresa, os dados técnicos do projeto, bem como o perfil e atribuições dos profissionais participantes. Além disso, foi possível identificar quais disciplinas estavam envolvidas no processo e quais as aprovações legais e técnicas foram demandadas. Já a entrevista, a primeira parte conta com perguntas direcionadas, e a segunda parte possui questões abertas, que necessitaram de mais discussão.

O roteiro de coleta dos dados foi estruturado por tópicos associadas aos objetivos da pesquisa: processo de projeto arquitetônico; Modelagem da Informação da Construção (adoção do BIM); fluxo de trabalho e intercâmbio de informações; gestão do processo de projeto e das informações. É importante ressaltar que a utilização do termo "Caso" nesta pesquisa se refere diretamente ao projeto de arquitetura analisado, sendo o estudo aplicado com dois participantes da pesquisa.

A coleta dos dados foi realizada no local de trabalho dos participantes, sempre com agendamento prévio para que não atrapalhasse as atividades habituais. O período de coleta de dados para o caso único aqui apresentado teve duração de 3 meses, iniciando no mês de fevereiro de 2018 e finalizando no início do mês de maio de 2018 (Quadro 1).

\begin{tabular}{|c|c|c|}
\hline CONTATO & DATA & ATIVIDADE \\
\hline 10 & 14.11.2017 & CONTATO INICIAL \\
\hline 20 & 07.12 .2017 & AGENDAMENTO \\
\hline 30 & 07.02 .2018 & FORMULÁRIO + QUESTIONÁRIO \\
\hline 49 & 21.02 .2018 & DOCUMENTAÇÃO \\
\hline 50 & 22.02 .2018 & DOCUMENTAÇÃO \\
\hline 60 & 27.02 .2018 & DOCUMENTAÇÃO \\
\hline 70 & 28.02 .2018 & DOCUMENTAÇÃO \\
\hline 80 & 01.03 .2018 & DOCUMENTAÇÃO \\
\hline 9o & 05.03 .2018 & DOCUMENTAÇÃO \\
\hline 10 - & 06.03 .2018 & DOCUMENTAÇÃO \\
\hline 110 & 07.03 .2018 & DOCUMENTAÇÃO \\
\hline $12 \circ$ & 08.03 .2018 & DOCUMENTAÇÃO \\
\hline 13음 & 12.03 .2018 & DOCUMENTAÇÃO \\
\hline 140 & 13.03 .2018 & DOCUMENTAÇÃO \\
\hline 150 & 14.03 .2018 & DOCUMENTAÇÃO + ENTREVISTA \\
\hline 160 & 26.03 .2018 & DOCUMENTAÇÃO + ENTREVISTA \\
\hline 179 & 07.05 .2018 & DOCUMENTAÇÃO \\
\hline 180 & 07.05 .2018 & PENDÊNCIAS \\
\hline 190 & 29.06 .2018 & VALIDAÇÃO DO MAPA DE PROCESSO \\
\hline
\end{tabular}

Fonte: Barros (2018). 
Nesta pesquisa foram utilizadas diferentes ferramentas que deram suporte para a elaboração do trabalho. Para a transcrição dos áudios das entrevistas foram usados dois recursos, o Voicemetter e o Voice Notepad, e para modelagem e análise processo do projeto foi utilizado o software Bizagi BPMN Modeler.

Após os dados coletados, realizou-se o tratamento dos mesmos a partir da transcrição, os dados foram organizados e cada instrumento de coleta teve um tratamento específico para realização da análise destes resultados, como pode ser visto na Figura 1.

Figura 1 - Tratamento dos dados

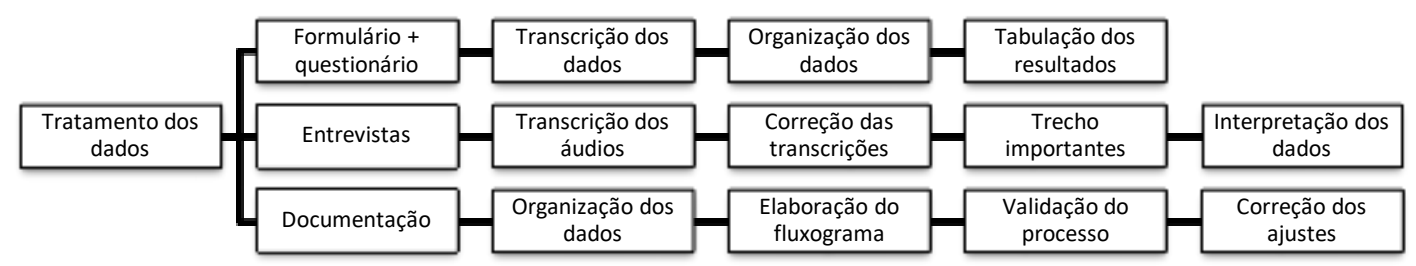

Fonte: Barros (2018).

Os dados adquiridos com o formulário e o questionário foram transcritos para um arquivo na plataforma de edição de textos Word e em seguida foram organizados por Caso, para logo depois serem tabulados.

Para análise dos dados nas entrevistas, num primeiro momento as transcrições dos áudios foram corrigidas e em seguida foram inseridas em um documento correspondente ao roteiro de coleta de dados, onde foram destacados alguns trechos considerados mais relevantes ao estudo. O critério utilizado para essa seleção consiste na fala por parte dos participantes da pesquisa, de termos e palavras-chaves associadas aos objetivos da pesquisa e a análise do conteúdo seguiu este critério.

Já os dados coletados pela análise da documentação foram estruturados por data, no caso a última data em que os arquivos (projeto em pdf, atas e planilhas) e os modelos BIM foram modificados, para otimizar a visualização das interações das disciplinas durante o processo de projeto. Esta forma de organização possibilitou uma melhor compreensão do processo, visto que eram muitos arquivos e modelos BIM a serem analisados. A disposição dos dados obtidos com a análise da documentação ocorreu em quadros, onde se estruturou o dado coletado da forma mais detalhada para mais simplificada, ou seja, as informações foram sintetizadas e ordenadas. Esses quadros foram organizados inicialmente por dia, em seguida por semanas, e depois por mês, sempre tendo como base as etapas de projeto. Esta organização da informação de projeto resultou no mapa de processo de projeto em BIM apresentado neste artigo.

O mapeamento do fluxo de informações foi realizado na plataforma de modelagem de processo Bizagi BPMN Modeler, sendo estruturado horizontalmente na parte superior pelas etapas de projeto e na barra lateral esquerda pelas disciplinas envolvidas no processo de projeto, conforme as entregas realizadas a empresa de arquitetura. Após a concepção do mapa de processo, o mesmo foi impresso para verificação com os participantes da pesquisa, e com a validação, foram realizadas as correções, sendo encaminhado novamente para avaliação final.

Para análise dos resultados, os dados foram organizados levando em consideração os objetivos da pesquisa. Deste modo, a estruturação da seção dos resultados ocorreu da seguinte forma: Caracterização do caso, Fluxo de informações entre disciplinas e Gestão das informações e do processo. 


\section{Resultados e discussões}

O projeto analisado neste trabalho foi desenvolvido por um escritório de arquitetura atuante na cidade de Florianópolis/SC há mais de 27 anos e que iniciou o uso do BIM em 2009. Com base nos dados adquiridos com o formulário de caracterização a empresa possui 14 funcionários. Destes, um mesmo profissional ocupa o cargo de diretor técnico e gerente de projeto, quatro coordenadores de projeto, quatro projetistas, quatro estagiários classificados como desenhistas e uma assistente administrativa. A empresa atua nos segmentos de arquitetura de interiores, arquitetura residencial, arquitetura comercial e arquitetura hospitalar. Em relação aos serviços prestados, a empresa elabora projeto de arquitetura, projeto de interiores, orçamento e estimativa de custo.

O projeto analisado corresponde ao Instituto de Cardiologia de Santa Catarina (ICSC) localizado em São José/SC. A concepção do projeto arquitetônico teve início em 13 de outubro 2015 e possuía previsão para finalização em outubro de 2018, totalizando 36 meses para conclusão do projeto, sendo elaborado até a etapa de Projeto Executivo (PE). O projeto possui $26.207,79 \mathrm{~m}^{2}$ de área do terreno e um total de $38.446,87 \mathrm{~m}^{2}$ de área construída. O cliente contratante deste projeto foi a Secretaria de Estado de Saúde - Fundo Estadual de Saúde/SC. É importante ressaltar que até a final da coleta de dados e desenvolvimento do trabalho, a elaboração do projeto não havia sido finalizada.

A partir da análise da documentação, foram identificadas 25 disciplinas envolvidas no processo: Serviços Topográficos; Serviços Geotécnicos; Projeto de Arquitetura; Projeto de Interiores; Projeto de Paisagismo; Projeto de Impermeabilização; Projeto de Drenagem Pluvial; Projeto de Estrutura e Fundações; Projeto de Engenharia Clínica; Projeto de Fachada; Projeto de Instalações Hidráulico-Sanitárias; Projeto de Instalações Elétricas Prediais; Projeto de Instalações de Gases Medicinais; Projeto de Instalações de Ar Condicionado; Projeto de Instalações Cabeamento e Lógica; Projeto de Instalações de Proteção e Combate a Incêndio; Projeto de Proteção Radiológica; Projeto e Homologação do Heliponto; Projeto de Comunicação e Sinalização Universal; Coordenação e compatibilização de projetos; Orçamentação.

Todavia os participantes da pesquisa mencionaram mais quatro disciplinas: Projeto de Instalações de Sistema de Segurança e CFTV; Projeto de Atenuação Acústica; Projeto de Sistema de Vapor; e Projeto de Sistema de Refrigeração. Todavia, ainda não estavam presentes no processo, resultando assim 29 disciplinas. Sendo que estas quatro não foram consideradas neste trabalho, pois não apareceram durante a coleta dos dados na análise da documentação.

Neste projeto, existem dois profissionais responsáveis pela gestão do processo, um é o coordenador de projetos de arquitetura (intitulado Participante 1), responsável pela validação das informações do projeto e o outro é o coordenador de compatibilização (intitulado Participante 2), responsável pela validação das informações do modelo. Ambos fazem parte do quadro de funcionários da empresa analisada neste estudo.

\section{Fluxo de informações entre disciplinas}

De acordo com os participantes da pesquisa, o processo de projeto teve início com a elaboração do programa de necessidade junto ao cliente e com o levantamento de informações do terreno. Segundo os participantes a estruturação do Programa de Necessidade (PN) levou cerca de 9 meses, devido aos ajustes e demandas do cliente. Com base nisso, os projetistas da empresa de arquitetura elaboraram os fluxogramas do projeto, com a delimitação dos setores e ambientes da edificação e o estudo de massas para aprovação do cliente. 
Foi nesta etapa que teve início o contato com as demais disciplinas de projeto para que algumas informações já fossem validadas desde o início como pode ser observado no seguinte trecho da entrevista "a gente já vê o que vai precisar de cada profissional e responde já de antemão". É importante mencionar que para a elaboração das outras etapas os períodos foram diferentes e que o somatório final não coincide com o tempo demandado ao projeto. Em virtude das etapas de projeto se interligarem, retrabalhos ocorriam e os ajustes de propostas eram essenciais, pois para iniciar uma etapa muitas vezes a anterior ocorria em paralelo devido alterações necessárias pelas compatibilizações de projeto. Deste modo, o Estudo Preliminar (EP) levou cerca de 20 meses para ser desenvolvido, enquanto que o Anteprojeto (AP) teve em média 15 meses de duração e o Projeto Executivo (PE) aproximadamente 17 meses. Estes períodos foram analisados a partir da coleta de dados com base nas datas dos arquivos e dos modelos BIM disponibilizados pelas disciplinas envolvidas, tanto os que foram enviados pela empresa, como os que foram recebidos dos demais profissionais.

A Figura 2 apresenta o mapa de processo observado, sendo que na vertical estão as etapas de projeto e na horizontal os agentes envolvidos representados pelo cliente contratante e demais tipos de projeto. A Figura 2 pode ser descarregada em alta resolução como material suplementar. A Figura 3 destaca na etapa de Programa de Necessidades (PN) os arquivos entregues pelas disciplinas de Projeto de Instalações Hidráulico-Sanitárias, Projeto de Instalações Elétricas Prediais, Projeto de Instalações de Gases Medicinais, quanto ao Programa de Necessidades (PN) e Lista de Entregáveis. A Lista de Entregáveis corresponde a um documento em que estão associados às entregas da disciplina de projeto organizadas por etapa, sendo essas entregas definidas por percentual, a exemplo do Projeto de Instalações Elétricas Prediais: Programa de Necessidade (2\%); Estudo Preliminar (10\%); Anteprojeto (20\%); Projeto para Licenciamento (18\%); Projeto Básico (17\%); Projeto Executivo (18\%); Entrega Final (15\%).

É importante ressaltar, que foi possível observar com a análise da documentação que as entregas das disciplinas de projeto não ocorreram simultaneamente. Os períodos foram distintos, mesmo sendo apresentados no mapa de processo da Figura 3 de modo alinhado. Deste modo, pode-se concluir que o processo foi integrado, mas não simultâneo, devido ao fato de que para o processo ser integrado, é necessário que ocorram interações, onde os dados se complementam. Já o sentido de simultâneo está relacionado a um processo que ocorre ao mesmo tempo, em paralelo, e isto não foi identificado na pesquisa. O Projeto de Arquitetura sempre esteve uma etapa antecipada em relação às outras disciplinas e os projetos foram se complementando, conforme mencionado pelos participantes quanto a disponibilização dos arquivos e modelos BIM.

Ainda de acordo com os participantes da pesquisa, depois do Estudo Preliminar (EP) do projeto aprovado, foi desenvolvido o Projeto Legal ou Projeto para Licenciamento (PL) em duas etapas, um para aprovação na Prefeitura Municipal e o outro para a aprovação na Vigilância Sanitária conforme a Resolução - RDC $n^{\circ} 50^{(2)}$, como pode ser visto na Figura 4. A partir daí a proposta foi evoluindo para a etapa de Projeto Básico (PB), para assim poder seguir para a etapa de Projeto Executivo (PE).

Relacionado a comunicação, foram utilizados relatórios digitais no BIM Collaboration Format (BCF) gerados a partir da compatibilização dos modelos recebidos no esquema de dados IFC, e essa troca ocorreu via e-mail. De acordo com os participantes da pesquisa, a equipe de projetos também fez uso de repositório (ownCloud) para comunicação com as demais disciplinas. Conforme mencionado durante a entrevista, inicialmente os arquivos e modelos BIM eram postados todo mês, porém, no decorrer do processo e com a demanda cada vez maior, principalmente no projeto executivo, começaram a ser postados semanalmente. 
BARROS, Roberta Augusta Menezes Lopes de; LIBRELOTTO, Lisiane Ilha; MEDINA, Franchesca

Modelo BIM integrado gerindo o fluxo de informações no processo de projeto

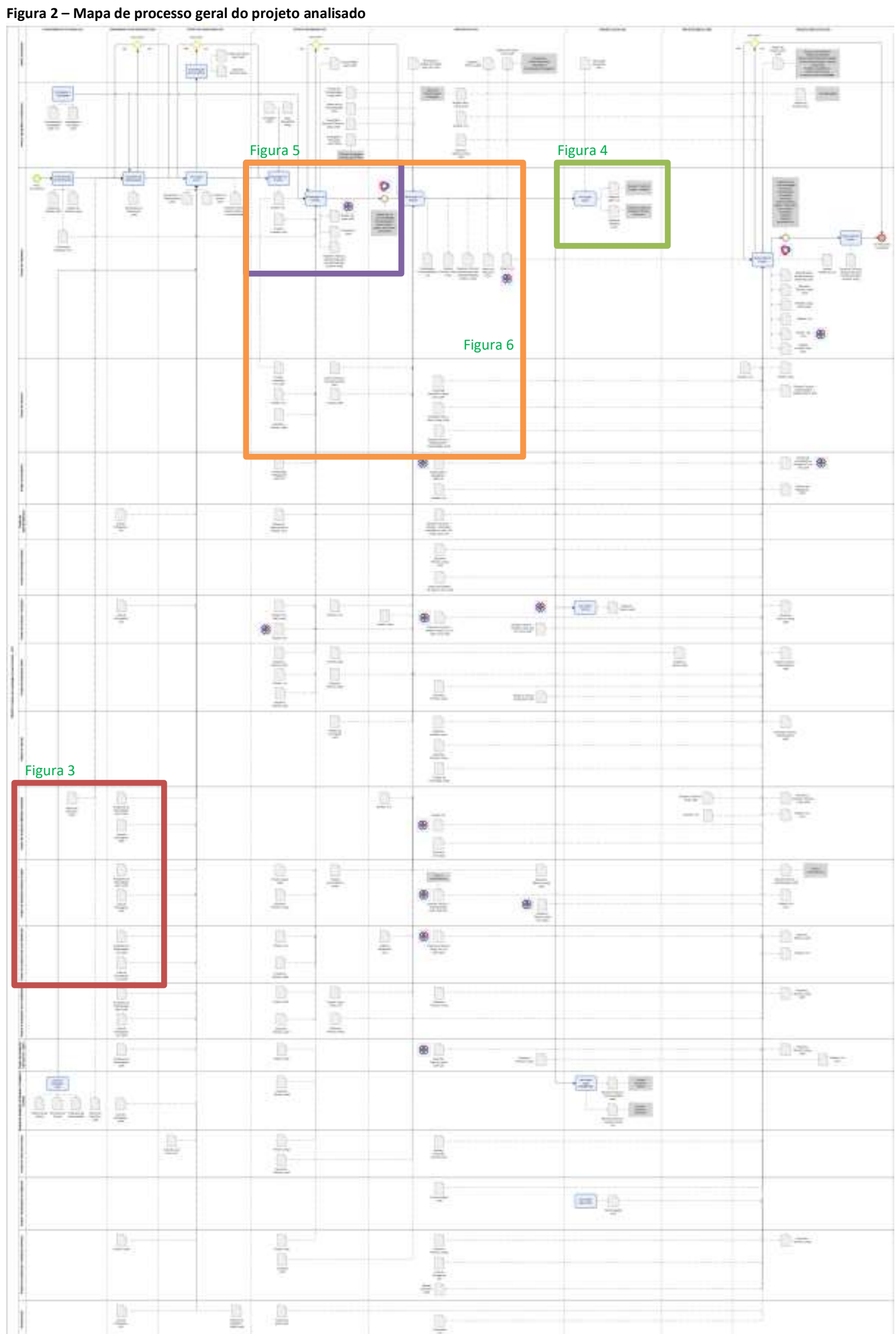

Fonte: Barros (2018). 
Figura 3 - Detalhe do mapa de processo geral para a fase de Programa de Necessidades (cinza) e disciplinas Projeto de Instalações HidráulicoSanitárias, Projeto de Instalações Elétricas Prediais, Projeto de Instalações de Gases Medicinais

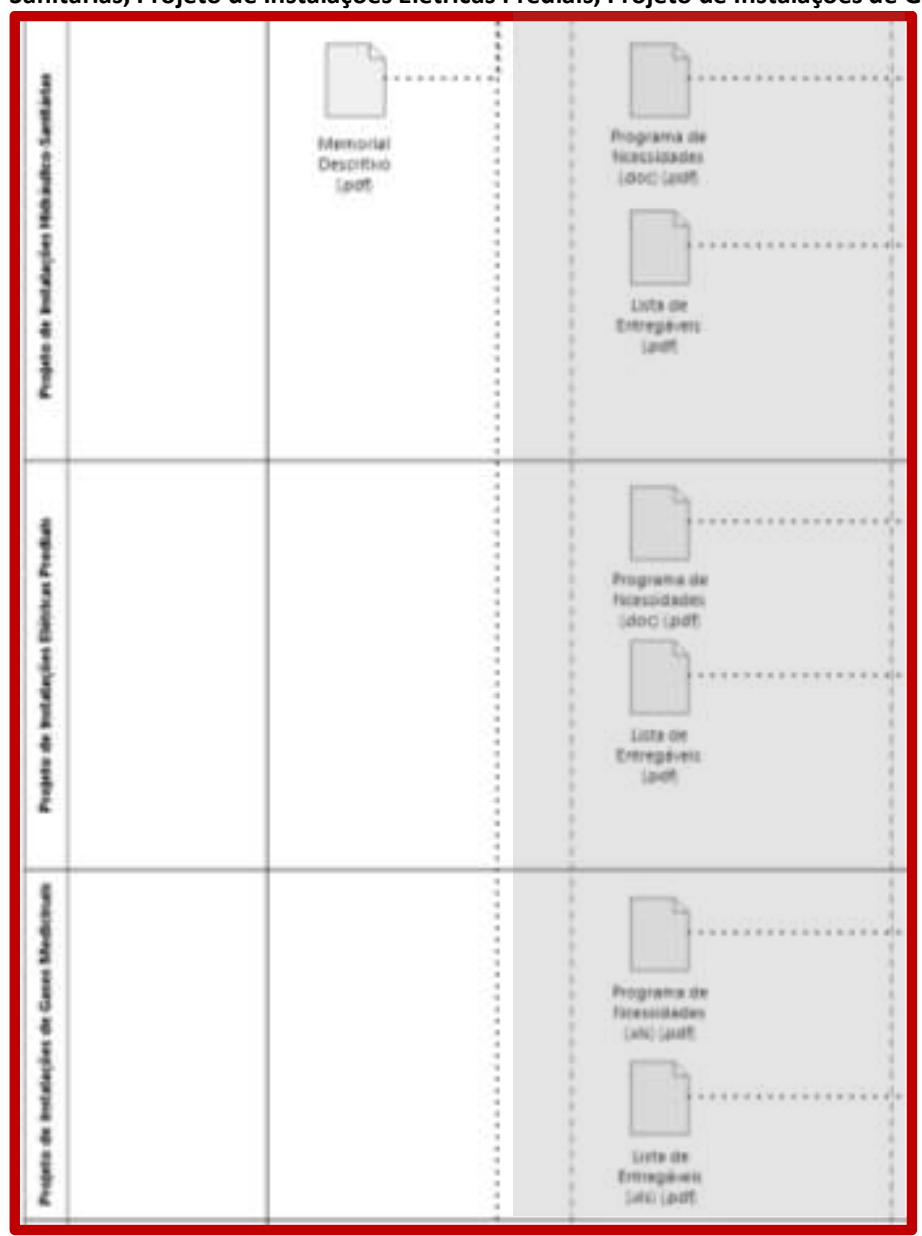

Fonte: Barros (2018).

Figura 4 - Detalhe do mapa de processo geral para a fase de Projeto Legal e disciplina Projeto Arquitetônico

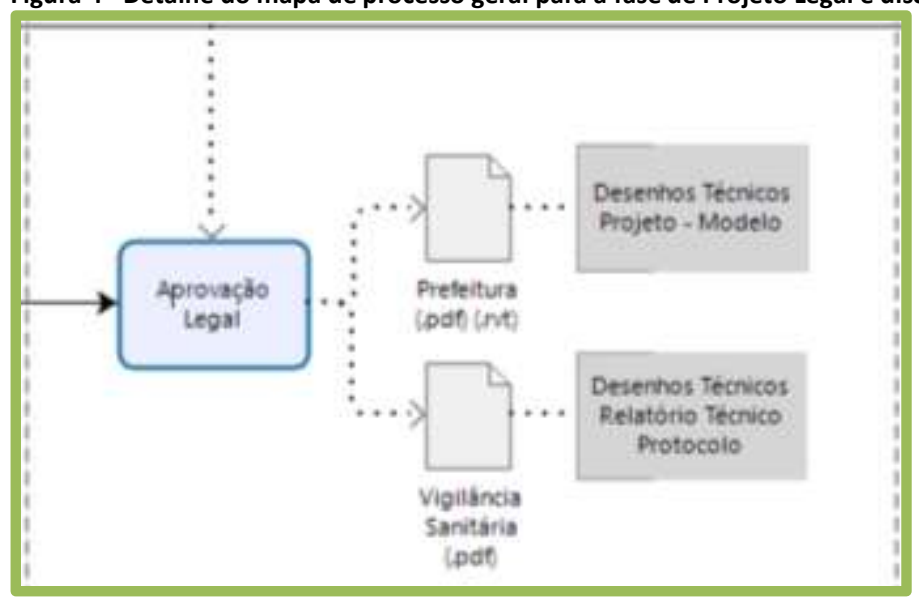

Fonte: Barros (2018).

A Figura 5 apresenta um recorte do mapa de processo relacionado ao Projeto de Arquitetura, durante o Estudo Preliminar (EP) e parte do Anteprojeto (AP). No Estudo Preliminar observou-se uma demanda de tempo maior de elaboração do projeto, como já mencionado anteriormente, totalizando 20 meses. É possível identificar no Estudo Preliminar a geração de Pranchas de Conceito, Modelos de Estudo, Perspectiva e Desenhos Técnicos (planta base para complementares em formato .dwg). Destaca-se também os relatórios de compatibilização de projeto (em BCF) desenvolvidos no 
Anteprojeto (AP), que ocorreram também na etapa de Projeto Executivo (PE), como pode ser visto no mapa de processo geral da Figura 2. Desta foram, a compatibilização dos projetos aconteceu em mais de uma etapa de projeto e isto pode estar associado a disponibilização das informações de modo antecipado pelos profissionais. Assim, percebe-se que houve facilitação na compatibilização dos projetos, sendo esta uma das principais vantagens adquiridas com o processo BIM em comparação com o processo tradicional de projeto, no qual este procedimento ocorria apenas ao final da proposta. E com a utilização destes recursos, também foi possível a gestão do processo.

Figura 5 - Detalhe do mapa de processo geral para a fase Estudo Preliminar e Anteprojeto (cinza) e disciplina Projeto Arquitetônico

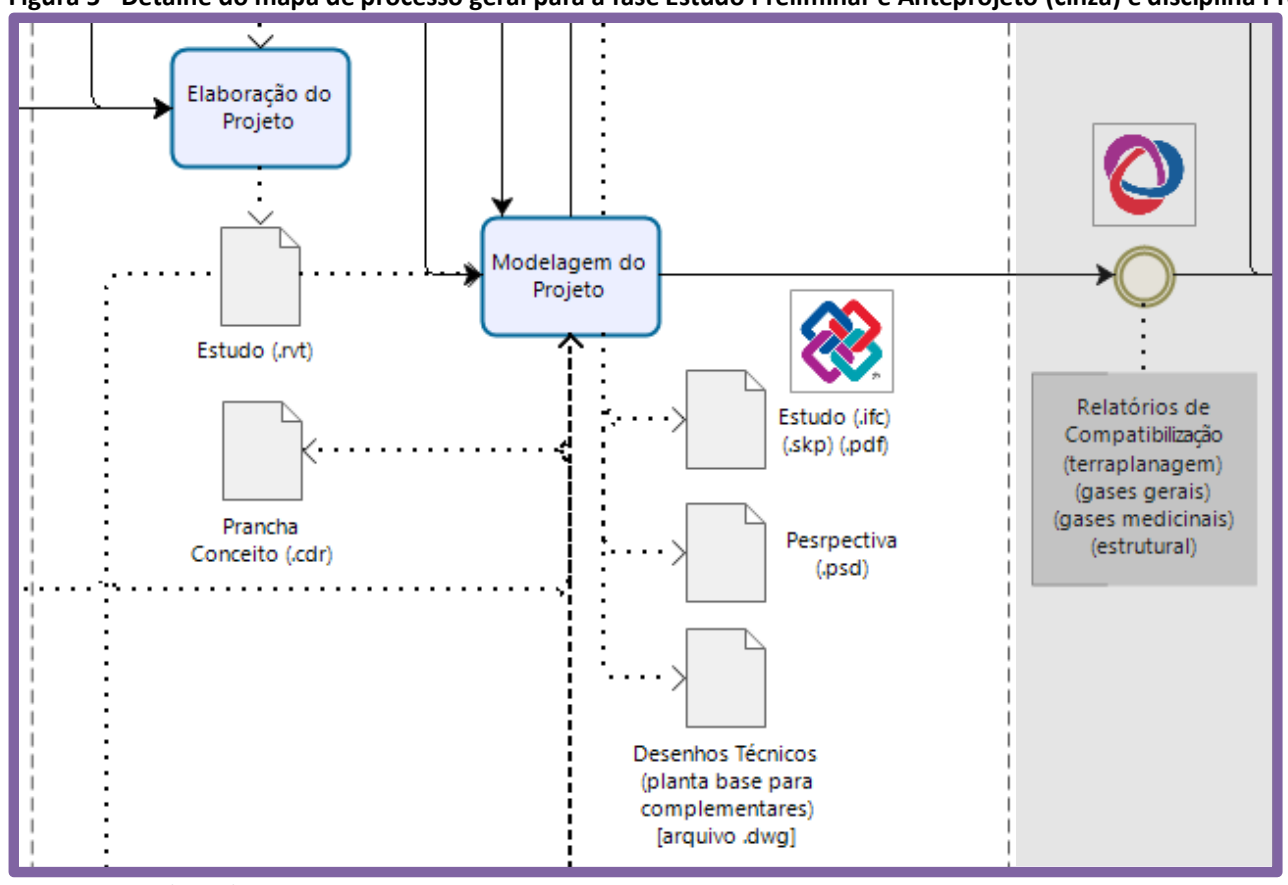

Fonte: Barros (2018).

Segundo os participantes da pesquisa, o modelo BIM disponibilizado pelas disciplinas era adicionado no repositório de compartilhamento e armazenamento do servidor da empresa, porém um modelo local continuava sendo desenvolvido dentro da empresa de arquitetura. Assim que as disciplinas liberavam seus respectivos modelos BIM no repositório de compartilhamento, a equipe de projetos do escritório atualizava diretamente o projeto arquitetônico, criando um modelo BIM integrado ${ }^{(3)}$ que incluía todos os modelos de todas as disciplinas complementares, mesclando todas as propriedades dos modelos individuais em um único banco de dados

Este aspecto possibilitou uma maior facilidade de visualização do projeto de forma integrada ainda nas fases preliminares de elaboração. A plataforma utilizada como repositório foi ownCloud, os arquivos eram inseridos em um computador na empresa (central de dados) e compartilhado com todos os envolvidos. Os arquivos e modelos BIM não eram inseridos diretamente na nuvem, mas em uma máquina, onde podia ser acessado remotamente pelas disciplinas de projeto.

O Participante 1 afirmou que as demais disciplinas de projeto envolvidas no processo se encontravam uma etapa anterior ao arquitetônico, mas em constante evolução, em razão de que todas elas interferem umas nas outras, ou seja, enquanto que o Projeto de Arquitetura estava sendo desenvolvido no Anteprojeto (AP), as disciplinas entregavam os arquivos e modelos BIM em nível de Estudo Preliminar (EP). Esta questão também foi constatada no mapa de processo como mostra a Figura 6. 
Figura 6 - Detalhe do mapa de processo geral para a fase Estudo Preliminar e Anteprojeto (cinza) e disciplina Projeto Arquitetônico (laranja) e Projeto de Interiores

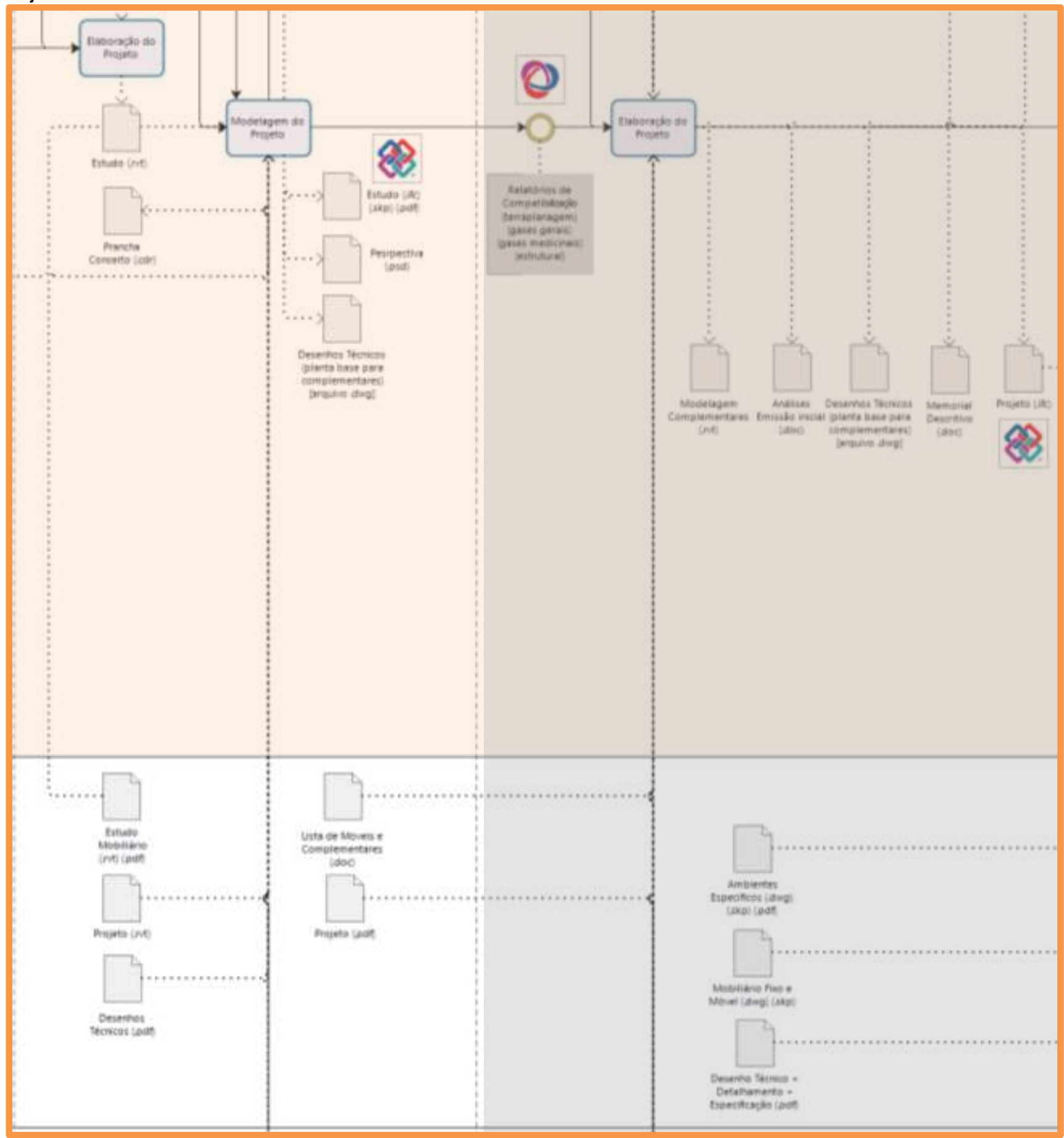

Fonte: Barros (2018).

É possível perceber que os arquivos gerados pela disciplina de Projeto de Interiores encontram-se uma etapa anterior se comparada à disciplina de Projeto de Arquitetura, ao identificar que a Lista de Móveis e Complementares (.doc) e o Projeto (.pdf) entregues no Estudo Preliminar (EP) serviram como dados de entrada para a Elaboração do Projeto na etapa de Anteprojeto (AP). Foi observado que as disciplinas iam gradativamente complementando o Projeto de Arquitetura, que consistiu como a base principal do processo deste projeto, ou seja, em o modelo integrado do projeto.

Isto corresponde ao fato de que neste projeto a base central foi o Projeto de Arquitetura como descrito pelo Participante 1 na entrevista, "mas é sempre assim, o arquitetônico 
norteia todos eles". Sendo que esta realidade pode ocorrer em um processo BIM ou tradicional, pois este fluxo de trabalho acontece na maioria das vezes, não sendo relacionado apenas ao BIM. Todavia, segundo os participantes da pesquisa desde o início do processo foram delimitadas as diretrizes, como também foram feitas as solicitações e discussões de projeto com as demais disciplinas para o entendimento de como cada sistema iria se comportar no todo. Este aspecto pode ser observado no seguinte trecho da entrevista "então cada engenheiro responsável, validou e deu seu parecer em relação a isso também, isso tudo até o anteprojeto". Porém, foram identificadas limitações durante o projeto, que segundo os participantes da pesquisa, relativas à insuficiência e indisponibilidade de informações técnicas para delimitação do projeto nas etapas iniciais, acarretando em decisões imprecisas e no tempo destinado para o Programa de Necessidades (9 meses), como mencionado anteriormente.

Observou-se ainda que o software utilizado para o desenvolvimento do Projeto de Arquitetura foi Revit Architecture (Autodesk), e para algumas disciplinas foram usados AutoCAD (Autodesk) e Sketchup (Trimble). Na coordenação o Navisworks (Autodesk) e para o gerenciamento dos dados foi utilizado o repositório ownCloud. É importante frisar que não foi possível detectar quais softwares BIM foram utilizados pelas demais disciplinas de projeto, visto que os modelos eram recebidos em IFC, como mostra a Figura 2 e a Figura 6. Sendo ainda identificado que algumas disciplinas de projeto não usavam softwares BIM, a exemplo da disciplina de Projeto de Instalações de Ar Condicionado. Entretanto, a solução encontrada pela empresa foi à terceirização interna do serviço de modelagem. A transcrição do projeto em CAD para BIM ocorreu dentro da própria empresa por um profissional terceirizado. Este aspecto evidenciou ainda mais a necessidade de se trabalhar com parceiros que utilizem softwares BIM, para que de fato o processo ocorra de modo integrado. Deste modo, como identificado no estudo, existem formas de inserir as disciplinas que ainda não utilizam o BIM em seu processo de trabalho, mesmo que os projetos não façam uso dos benefícios do BIM, estes podem sim fazer parte do processo de desenvolvimento dos projetos.

De acordo com os participantes da pesquisa e com base nos dados analisados, foram identificadas vantagens e desvantagens com a adoção e uso do BIM no processo de projeto. Como benefício, destacaram-se: maior controle da informação, melhor interação entre os profissionais envolvidos no processo, facilidade de visualizar o projeto e melhoria da compatibilidade entre as disciplinas. Em relação às desvantagens, observou-se uma aderência parcial dos envolvidos à disponibilização dos modelos de informação nos prazos estipulados e a variedade de ferramentas BIM e CAD utilizadas assim como projetos entregues em PDF dificultando a interoperabilidade e reuso de modelagens.

\section{Gestão das informações e do processo}

Um aspecto mencionado pelo Participante 2, é que o modelo integrado do projeto congregava a última versão de cada modelo disponibilizado pelos profissionais, permitindo o controle e monitoramento das informações de projeto. Esta associação ocorria por meio de links e localmente (central de dados utilizando um computador na empresa). Foi relatado também que o registro e a documentação das informações do projeto aconteceram por atas de reunião (foram gerados 63 arquivos) e pela definição das tarefas nas plataformas de gerenciamento online, o Basecamp e o Planner.

De acordo com o Participante 1, a utilização dessas plataformas serviu principalmente para controle interno dos profissionais e apenas para cobrança com todas as disciplinas, na justificativa de que é um processo de trabalho distribuído com protocolos próprios, e implantar as ferramentas Basecamp e Planner em outras empresas não seria viável, 
porque cada profissional possui seu modo trabalho estabelecido. Também foi apontado que as plataformas de gerenciamento online, auxiliaram bastante, especialmente na organização, mas não na otimização do processo. Em razão de que existe a necessidade de um profissional especializado com funções e atribuições exclusivas à gestão do processo, e foi observado que isto não ocorreu de forma efetiva dentro da empresa.

Conforme afirmativa do Participante 1 a colaboração ocorreu com toda a equipe desde o início, e a gestão foi feita pela empresa que desenvolveu também o Projeto de Arquitetura. Todavia é importante ressaltar que a colaboração foi parcial, pois ocorreu pelo compartilhamento dos modelos visando o modelo BIM integrado. As responsabilidades de gestão estavam relacionadas a coordenação do projeto, associado a prazos de entrega, soluções e resoluções de problemas. A gestão foi centralizada pela empresa de arquitetura, e segundo citado pelos participantes, as disciplinas não tinham contato direto entre si, as informações eram enviadas a equipe de projetos das empresas parceiras, estes eram responsáveis por repassar e transferir o modelo ou a informação de projeto para as demais, e do mesmo modo com o cliente. O repositório, no servidor local da empresa, era utilizado para compartilhamento e armazenamento de todos os arquivos e modelos relacionados ao projeto.

Como é exposto no seguinte trecho da entrevista "é uma responsabilidade nossa coordenar todas as informações para passar para as equipes, assim como é responsabilidade nossa receber todas as demandas do cliente e passar para as equipes".

Assim, foi verificado neste projeto o papel do arquiteto enquanto gestor do processo, como também, foi identificado nos resultados do fluxo de informações entre as disciplinas e no discurso dos participantes, o Projeto de Arquitetura como norteador de todo este processo. Devido ao fato de que era utilizado um modelo integrado gerido pela disciplina de Arquitetura que recebia todos os outros modelos.

Neste projeto foi observado ainda, o uso de "Lista de Entregáveis" o que se caracterizou como um diferencial para planejamento, controle e monitoramento das informações ao longo da gestão do processo de projeto. Com o BIM, a gestão do processo foi facilitada devido a troca e o compartilhamento dos arquivos e modelos de forma mais rápida e precisa, em comparação ao processo tradicional de projeto. Através da utilização do repositório de compartilhamento e armazenamento, servindo como uma central de dados para o projeto que podia ser acessada por todos os envolvidos no processo.

\section{Conclusão}

Este estudo caracterizou um processo de projeto parcialmente colaborativo de empresa de arquitetura que responde à licitação governamental de projeto em BIM. O estudo de caso é de um processo de projeto em BIM que envolve 29 disciplinas e a coordenação associada demonstrando o porte e complexidade do projeto desenvolvido. Verificou-se alteração de duração das etapas de projeto. A elaboração do Estudo Preliminar (EP) levou cerca de 20 meses, se comparado com o Anteprojeto (AP) que durou em média 15 meses e o Projeto Executivo (PE) que durou aproximadamente 17 meses. O que difere do tempo planejado ao desenvolvimento do projeto, devido ao fato de que as etapas de projeto se interligavam, ocorriam retrabalhos e reajustes. Assim, as etapas ocorriam em paralelo em virtude das alterações necessárias pelas compatibilizações de projeto.

Observou-se que as entregas das disciplinas, não ocorreram simultaneamente. As datas das entregas foram diferentes, mesmo sendo apresentados no mapa de processo de modo alinhado em uma mesma etapa de projeto. Com isso, é possível concluir que o processo de elaboração de projeto foi integrado, mas não simultâneo. Entretanto, 
mesmo não ocorrendo um trabalho síncrono houve ganhos de gestão proporcionado pelo maior conhecimento no fluxo de trabalho dos envolvidos no processo de projeto.

A gestão foi centralizada pela empresa de arquitetura, e conforme citado pelos participantes, as disciplinas não tinham contato direto entre si, as informações eram enviadas a equipe de projetos das empresas parceiras, estes eram responsáveis por repassar e transferir o modelo ou a informação de projeto para as demais, e do mesmo modo com o cliente. O repositório era utilizado somente para entrega dos modelos e para a centralização da coordenação da empresa de arquitetura.

Outro aspecto identificado no mapa de processo e no discurso dos participantes da pesquisa se refere à disciplina de Projeto de Arquitetura como puxadora do processo. As demais disciplinas de projeto envolvidas se encontravam uma etapa anterior ao projeto arquitetônico, mas em constante evolução e acompanhamento das interferências por meio da análise do modelo BIM integrado. Deste modo, as disciplinas iam gradativamente complementando o Projeto de Arquitetura.

Uma das principais conclusões deste estudo está relacionada à percepção do projeto como um processo e não apenas como um produto a ser entregue, principalmente associado à demanda de tempo destinada à sua elaboração. Onde se faz necessário à compreensão do processo por todos profissionais envolvidos, pois o diálogo precisa ser recorrente, e as trocas e o compartilhamento das informações devem ser efetivas para que o processo se mantenha integrado desde as etapas iniciais.

Assim, a principal contribuição deste estudo, para a melhoria do processo de projeto em arquitetura, está na demonstração de um processo de projeto que tenta se adaptar às mudanças necessárias para a adoção do BIM. Verifica-se que o processo analisado ainda possui vícios ou vestígios do processo em CAD tradicional e que existe espaço para melhoramentos, mas que mesmo assim foram identificados benefícios na integração da solução projetual. Destaca-se como benefício um maior controle da informação, melhor interação entre os profissionais envolvidos no processo, facilidade de visualização do projeto, bem como a melhoria da compatibilidade entre as disciplinas. Já em relação as desvantagens, foi observado uma aderência parcial dos envolvidos à disponibilização dos modelos de informação nos prazos estipulados e a variedade de ferramentas BIM e CAD utilizadas, bem como projetos entregues em PDF dificultando a interoperabilidade e reuso de modelagens.

\section{Agradecimentos}

Agradecimento a CAPES pelo apoio financeiro; a Universidade Federal de Santa Catarina pelo ambiente propício a este estudo; ao Grupo de Pesquisa Virtuhab pelas contribuições intelectuais; e a empresa pela disponibilidade em participar da pesquisa e colaboração prestada.

\section{Notas}

(1) http://plataformabrasil.saude.gov.br/login.jsf. A documentação utilizada na pesquisa está condicionada ao cumprimento dos requisitos determinados pela Resolução N510/2016. Sendo esta, aprovada com o título: "GESTÃO DO PROCESSO E FLUXO DE INFORMAÇÕES EM PROJETOS BIM 3D: Estudo de caso em empresas de arquitetura em Florianópolis/SC", com numeração do parecer 2.562.664 no dia 26 de Março de 2018.

(2) Resolução - RDC $n^{\circ}$ 50, de 21 de fevereiro de 2002. Dispõe sobre o Regulamento Técnico para planejamento, programação, elaboração e avaliação de projetos físicos de estabelecimentos assistenciais de saúde.

(3) A compreensão de modelo integrado é segundo o termo Integrated Model como apresentado no BIM Dictionary em https://bimdictionary.com/en/integrated-model/1. 


\section{Referências}

ANTUNES, C. E.; SCHEER, S. Requisitos de informação e mapas do processo de projeto de estruturas em concreto armado: um estudo de caso utilizando a metodologia IDM. PARC Pesquisa Em Arquitetura E Construção, Campinas, SP, v. 5, n. 1, p. 18-34, 2014. DOI: https://doi.org/10.20396/parc.v5i1.8634541

ARAYICI, Y., COATES P., KOSKELA, L., KAGIOGLOU, M.; USHER, C.; O'REILLY, K. BIM adoption and implementation for architectural practices. Emerald Structural Survey, v. 29, Issue: 1, p. 7-25, 2011.

DOI:https://doi.org/10.1108/02630801111118377

ARCARI, E. do A.; PEREIRA, A. T. C.; COSTACURTA JUNIOR, R.; MANSANO, I. Interoperabilidade: Um desafio para o Processo de Modelagem Parametrizada de Detalhes Arquitetônicos e sua Materialização. In: SOCIEDADE IBEROAMERICANA DE GRÁFICA DIGITAL, 19, 2015, Florianópolis. Anais [...]. São Paulo: Blucher, 2015. p. 341-349. DOI: 10.5151/despro-sigradi2015-80143

AZHAR, S.; KHALFAN, M.; MAQSOOD, T. Building Information Modelling (BIM): now and beyond. Construction Economics and Building, v. 12, Issue: 4, p. 15-28, 2015. DOI: https://doi.org/10.5130/AJCEB.v12i4.3032

BARISON, M. B.; SANTOS, E. T. Ensino de BIM: tendências atuais no cenário internacional. Gestão \& Tecnologia de Projetos, São Paulo, v. 6, p. 67-80, 2012. DOI: https://doi.org/10.4237/gtp.v6i2.218

BARISON, M. B.; SANTOS, E. T. O papel do arquiteto em empreendimentos desenvolvidos com a tecnologia BIM e as habilidades que devem ser ensinadas na Universidade. Gestão \& Tecnologia de Projetos, São Paulo, v. 11, n. 1, p. 103-120, 2016. DOI: https://doi.org/10.11606/gtp.v1111.102708

BARROS, N. N.; SILVA, V. G. da.. BIM na avaliação do ciclo de vida de edificações: revisão da literatura e estudo comparativo. PARC Pesquisa Em Arquitetura E Construção, Campinas, SP, v. 7, n. 2, p. 89-101, 2016. DOI: http://dx.doi.org/10.20396/parc.v7i2.8645401.

BARROS, R. A. M. L. de. PROCESSO DE PROJETO E FLUXO DE INFORMAÇÕES EM BIM: Estudos de Caso em Florianópolis/SC. 2018. 219 f. Dissertação (Mestrado em Arquitetura e Urbanismo) - Universidade Federal de Santa Catarina, Florianópolis, 2018.

BOMFIM, C. A. A.; MATOS, P. C. C. DE; LISBOA, B. T. W. Gestão de Obras com BIM - Uma nova era para o setor da Construção Civil. In: SOCIEDADE IBERO-AMERICANA DE GRÁFICA DIGITAL, 20, 2016, Buenos Aires. Anais [...]. São Paulo: Blucher, 2016. p. 556-560. DOI: http://dx.doi.org/10.5151/despro-sigradi2016-724

CAMPESTRINI, T. F. (Org.). Entendendo o BIM: Uma visão do projeto de construção sob o foco da informação. 1. ed. Curitiba: Editora UFPR, 2015. 115p.

CARVALHO, M. A. Eficácia de interoperabilidade no formato IFC entre modelos de informação arquitetônico e estrutural. 2012. 222 f. Dissertação (Mestrado em Engenharia de Construção Civil) - Universidade Federal do Paraná, Curitiba, 2012.

CHECCUCCI, E. S. Ensino-aprendizagem de BIM nos cursos de graduação em Engenharia Civil e o papel da Expressão Gráfica neste contexto. 2014.235 f. Tese (Doutorado em Difusão do Conhecimento) - Universidade Federal da Bahia, Salvador, 2014.

CHEN, K.; LU, W.; PENG, Y.; ROWLINSON, S.; HUANG, G. Q. Bridging BIM and building: From a literature review to an integrated conceptual framework. International Journal of Project Management, v. 33, Issue: 6, p. $1405-1416,2015$. DOI: https://doi.org/10.1016/j.ijproman.2015.03.006

CRUZ, M. O.; CUPERSCHMID, A.; RUSCHEL, R. C. A incorporação de BIM no ensino do curso Técnico em Edificações. Gestão \& Tecnologia de Projetos, v. 12, n. 2, p. 117-134, 2017. DOI: http://dx.doi.org/10.11606/gtp.v12i2.131498.

COELHO, K. M.; SILVA, T. F.; MELHADO, S. Implementação da modelagem da informação da construção em empresa de arquitetura: um estudo de caso. In: ENCONTRO BRASILEIRO DE TECNOLOGIA DE INFORMAÇÃO E 
COMUNICAÇÃO NA CONSTRUÇÃO, 7, 2015, Recife. Anais [...]. Porto Alegre: ANTAC. São Paulo: Blucher, 2015. p. 696709. DOI: http://dx.doi.org/10.5151/engpro-tic2015-062

COSTA, J. M. C. da. Diagnóstico da Implantação do BIM em Empresas Construtoras com foco nos Processos de Planejamento, Orçamento e Controle de Obras. 2015. 197 f. Dissertação (Mestrado em Estruturas e Construção Civil) - Universidade Federal de São Carlos, São Carlos, 2015.

CRESWELL, J. W. Projeto de pesquisa: métodos qualitativo, quantitativo e misto. 2. ed. Porto Alegre: Artmed, 2007. Tradução de: Luciana de Oliveira da Rocha.

DELATORRE, J. P. M.; SANTOS, E. T. Introdução de novas tecnologias: o caso do BIM em empresas de Construção Civil. In: ENCONTRO NACIONAL DE TECNOLOGIA DO AMBIENTE CONSTRUÍDO, 15, 2014, Maceió. Anais [...]. Porto Alegre: ANTAC, 2014. p. 2842-2851. DOI: http://doi.org/10.17012/entac2014.135

\section{DELATORRE, V. D. POTENCIALIDADES E LIMITES DO BIM NO ENSINO DE ARQUITETURA: UMA PROPOSTA DE}

IMPLEMENTAÇÃO. 2014. 293 f. Dissertação (Mestrado em Engenharia da Arquitetura e Urbanismo) - Universidade Federal de Santa Catarina, Florianópolis, 2014.

DURANTE, F. K.; MENDES JR, R.; SCHEER, S.; GARRIDO, M. C. Avaliação de aspectos fundamentais para a gestão integrada do processo de projeto e planejamento com uso do BIM. In: ENCONTRO BRASILEIRO DE TECNOLOGIA DE INFORMAÇÃO E COMUNICAÇÃO NA CONSTRUÇÃO, 7, 2015, Recife. Anais [...]. Porto Alegre: ANTAC. São Paulo: Blucher, 2015. p. 641-653. DOI: http://dx.doi.org/10.5151/engpro-tic2015-057

EASTMAN, C.; TEICHOLZ, P.; SACKS, R. LISTON, K. Manual de BIM: Um guia de modelagem a informação da construção para arquitetos, engenheiros, gerentes, construtores e incorporadores. 1. ed. Porto Alegre: Bookman, 2014. Tradução de: Cervantes Gonçalves Ayres Filho et al. Revisão técnica: Eduardo Toledo Santos.

ELMUALIM, A.; GILDER, J. Architectural Engineering and Design Management BIM: innovation in design management, influence and challenges of implementation. Architectural Engineering and Design Management, v. 10, Issue: 3-4. p. 183-199, 2013. DOI: https://doi.org/10.1080/17452007.2013.821399

FARINA, H., COELHO, K. M. Impactos na coordenação de projetos assistida pela modelagem da informação da construção. In: ENCONTRO BRASILEIRO DE TECNOLOGIA DE INFORMAÇÃO E COMUNICAÇÃO NA CONSTRUÇÃO, 7, 2015, Recife. Anais [...]. Porto Alegre: ANTAC. São Paulo: Blucher, 2015. p. 61-74. DOI:

http://dx.doi.org/10.5151/engpro-tic2015-006

FERREIRA, T. V. G.; SANTOS, A. O. W. Análise situacional da implantação do BIM como apoio ao processo de projeto: estudo de caso em Maceió-AL. In: ENCONTRO BRASILEIRO DE TECNOLOGIA DE INFORMAÇÃO E COMUNICAÇÃO NA CONSTRUÇÃO, 7, 2015, Recife. Anais [...]. Porto Alegre: ANTAC. São Paulo: Blucher, 2015. p. 757-769. DOI: http://dx.doi.org/10.5151/engpro-tic2015-067

GOES, R. H. T. B.; SANTOS, E. T. Design coordination with Building Information Modeling: a case study. In: CIB W78W102, 2011, Sophia Antipolis. Proceedings [... ]. Sophia Antipolis, France: International Conference, 2011. p. 1-10.

KOWALTOWSKI, D. C. C. K.; MOREIRA, D. de C.; PETRECHE, J. R. D.; FABRICIO, M. M. (orgs). O processo de projeto em arquitetura. 1. ed. São Paulo: Oficina de Textos, 2011.

MAIA, B. L. ANALISE DO FLUXO DE INFORMAÇOES NO PROCESSO DE MANUTENÇÃO PREDIAL APOIADA EM BIM: ESTUDO DE CASO EM COBERTURAS. 2016. 101 f. Dissertação (Mestrado em Construção Civil) - Universidade Federal do Paraná, Curitiba, 2016.

MAKEBIM. Santa Catarina e Rio Grande do Sul firmam parceria para trocar experiências sobre o BIM. Disponível em: http://www.makebim.com/2016/11/17/santa-catarina-e-rio-grande-do-sul-firmam-parceria-para-trocarexperiencias-sobre-o-bim/. Acesso em: 27 maio 2018.

MENEZES, G. L. B. B. de. Breve histórico de implantação da plataforma BIM. Cadernos de Arquitetura e Urbanismo, v.18, n.22. 2011. p. 1-20. DOI: https://doi.org/10.5752/P.2316-1752.2011v18n22p152 
MIGILINSKASA, D.; POPOVB, V.; JUOCEVICIUSC, V.; USTINOVICHIUSD, L. The Benefits, Obstacles and Problems of Practical Bim Implementation. Procedia Engineering. v. 57, p. 767 - 774, 2013.

DOI:https://doi.org/10.1016/j.proeng.2013.04.097

MONTEIRO, A.; MARTINS, J. P. Building Information Modeling (BIM) - teoria e aplicação. In: ICEUBI, 2011, Corvilhã. Proceedings [... ]. Corvilhã, Portugal: International Conference on Engineering, 2011. p. 1-10.

MÜLLER, M. F. A interoperabilidade entre sistemas CAD de projeto de estruturas de concreto armado baseada em arquivos IFC. 2011. 129 f. Dissertação (Mestrado em Engenharia de Construção Civil) - Universidade Federal do Paraná, Curitiba, 2011.

OLIVEIRA, G. A.; SOUZA, K. A.; CABRERA, T. S.; FERREIRA, S. L. CONTRIBUIÇÃO PARA COORDENAÇÃO DE PROJETOS EM BIM ATRAVÉS DO BFC. In: Simpósio Brasileiro de Tecnologia da Informação e Comunicação na Construção, 1, 2017, Fortaleza. Anais [...]. Porto Alegre: ANTAC, 2017. p. 24-31

PEREIRA, A. P. C.; AMORIM, A. L. de. A implantação de BIM : usos, atividades e processos na fase inicial da projetação. In: SOCIEDADE IBERO-AMERICANA DE GRÁFICA DIGITAL, 20, 2016, Buenos Aires. Anais [...]. São Paulo: Blucher, 2016. p. 497-504. DOI: http://dx.doi.org/10.5151/despro-sigradi2016-470

ROKOOEI, S. Building Information Modeling in Project Management: Necessities, Challenges and Outcomes. Procedia - Social and Behavioral Sciences, v. 210, p. 87-95, 2015. DOI: https://doi.org/10.1016/j.sbspro.2015.11.332

ROMANO, F. V.; BACK, N.; OLIVEIRA, R. de. A Importância da Modelagem do Processo de Projeto para o Desenvolvimento Integrado de Edificações. In: I Workshop Nacional Gestão do Processo de Projeto na Construção de Edifícios, 2001, São Carlos. Anais [...]. São Paulo: EESC-USP, 2001. p. 1-5

RUSCHEL, R. C.; ANDRADE, M. L. V. X.; MORAIS, M. O ensino de BIM no Brasil: onde estamos? Ambient. constr. [online]. vol. 13, n. 2, pp. 151-165, 2013. DOI: http://dx.doi.org/10.1590/S1678-86212013000200012

SOUZA, L. A de; AMORIM, S. R. L.; LYRIO, A. de M. IMPACTOS DO USO DO BIM EM ESCRITÓRIOS DE ARQUITETURA: OPORTUNIDADES NO MERCADO IMOBILIÁRIO. Gestão \& Tecnologia de Projetos. São Paulo, v. 4, n. 2, p.26-53, 2009. DOI: https://doi.org/10.4237/gtp.v4i2.100

SOUZA, F. R; HISAMOTO, M.; SANTOS, E. T.; MELHADO, S. B. Abordagem para introdução do conceito BIM em empresas incorporadoras e construtoras brasileiras: Análise crítica sobre as posturas estratégicas, tática e operacional. In: ENCONTRO NACIONAL DE TECNOLOGIA DO AMBIENTE CONSTRUÍDO, 14, 2012, Juiz de Fora. Anais [...]. Porto Alegre: ANTAC, 2012. p. 338-349

YIN, R. K. Case Study Research: Design and Methods. 4. ed. Londres: Sage Publications, 2009.

\footnotetext{
${ }^{1}$ Roberta Augusta Menezes Lopes de Barros 1

Arquiteta e Urbanista. Mestre em Arquitetura e Urbanismo pela Universidade Federal de Santa Catarina. Endereço Postal: Rua João Pio Duarte Silva, 576 - Ed. Ilha Formosa, BL B Apto 203, Florianópolis, SC, Brasil, 88037-000

\section{Lisiane Ilha Librelotto 2}

Engenheira Civil. Doutora em Engenharia de Produção pela Universidade Federal de Santa Catarina. Professora na Universidade Federal de Santa Catarina, Centro Tecnológico, Departamento de Arquitetura. Endereço profissional: Departamento de Arquitetura e Urbanismo, Centro Tecnológico - UFSC, Florianópolis, SC, Brasil, 88040-900

\section{Franchesca Medina 3}

Arquiteta e Urbanista. Graduanda em Arquitetura e Urbanismo pela Universidade Federal de Santa Catarina. Endereço Postal: Rua João Pio Duarte Silva, 114 - Ed. Villa Vitoria, BL B Apto 206, Florianópolis, SC, Brasil, 88037-000
} 